Gazi University
Journal of Science
http://dergipark.gov.tr/gujs

\title{
Synthesis and Characterization of Poly (2-hydroxyethyl methacrylate) Homopolymer at Room Temperature via Reversible Addition-Fragmentation Chain Transfer (RAFT) Polymerization Technique
}

\author{
Ertan YILLDIRIM ${ }^{*}$ \\ Department of Chemistry, Faculty of Science, Gazi University, Besevler, Ankara 06500
}

\author{
Highlights \\ - PHEMA synthesized by RAFT technique at room temperature. \\ - PHEMA was successfully synthesized in a controlled manner under mild conditions. \\ - Detailed characterization of PHEMA by ATR-FTIR and NMR was performed. \\ - PHEMA contain carboxylic acid functional end group.
}

\section{Article Info}

Received: $17 / 04 / 2019$ Accepted: 19/08/2019

Keywords

$R A F T$

PHEMA

$N M R$

ATR-FTIR

\begin{abstract}
Synthesis and characterization of Poly (2-hydroxyethyl methacrylate) (PHEMA) by RAFT technique at room temperature was first reported in this study. In this context, molecular weight, monomer conversion and semi-logarithmic kinetic curves of the RAFT polymerization, which is one of the controlled-living polymerization techniques, were determined by ATR-FTIR and NMR at certain time intervals. Linear change of molecular weight and monomer conversion with time, semi-logarithmic kinetic curve to the first degree kinetics of the synthesized PHEMA shows that the growth of polymer chains in a controlled manner. PHEMA polymers synthesized by RAFT technique at room temperature without the use of catalyst and metal types have the potential to be easily used in bio applications. It is also important for peptide and protein adsorption that this polymer has functional properties due to the carboxylic acid at the end of the RAFT agent.
\end{abstract}

\section{INTRODUCTION}

Controlled / living radical polymerization techniques mainly consist of Atom-Transfer Radical Polymerization (ATRP), Reversible Addition-Fragmentation Chain Transfer (RAFT) Polymerization, and Nitroxide-Mediated Polymerization (NMP) [1-5]. These techniques have been used in many applications in recent years. Synthesized polymers; the compatibility with the first-order speed kinetics, the continuation of the polymerization until the monomer is finished, the production of polymers having low molecular weight distribution and most importantly, the polymerization in a controlled manner [6-8]. With the simultaneous and homogenous growth of polymer chains, many polymers were synthesized and the polymers containing the functional groups found a wide range of applications, in particular biocompatibility $[9,10]$.

RAFT polymerization, which is one of the controlled/living polymerization techniques in recent years, is more preferable to be applied to many monomers, to perform polymerization under mild conditions and to obtain polymers with functional end groups in the RAFT agent $[11,12]$. There are important disadvantages such as the difficult removal of the metal complexes used in ATRP from the medium as a result of polymerization and in NMP the initiation of polymerization at high temperatures $[13,14]$. Due to the negative conditions in ATRP and NMP, the RAFT technique has become interesting.

It is important to apply controlled/living polymerization techniques to monomers which have polar or functional groups. One of the best examples of these monomers is 2-hydroxyethyl methacrylate (HEMA). 
The HEMA monomer is polymerized by ATRP and RAFT technique. The detailed characterization of PHEMA obtained by ATRP technique at room temperature is available in literature [15]. Polymerization of HEMA monomer by RAFT technique was performed on silicon disc surfaces at $75^{\circ} \mathrm{C}$ and the properties of the surface were determined [16]. HEMA monomer has been used in many bioengineering and contact lens production due to its hydroxyl group [17,18]. In addition to these applications, it has found its place in a wide range from drug delivery to application in hydrogel synthesis $[19,20]$. The controlled polymerization of the HEMA monomer is important for its use in these applications. The homogeneous distribution and control of polymer chains make the use of PHEMA advantageous in applications.

In this report, HEMA monomer was polymerized with DDMAT raft agent and 4,4-azobis cyanovaleric acid initiator in methanol/water (50\% -50\%) solution. Monomer conversion in one hour was observed to be up to $92 \%$. Samples from the polymer solution were taken at different time intervals to obtain ATR-FTIR and NMR spectra. The monomer conversion by the NMR technique, the semi-logarithmic kinetic curve and the molecular weights of the polymers were determined. PHEMA was successfully synthesized in a controlled manner under mild conditions with RAFT polymerization technique.

\section{MATERIAL AND METHODS}

\subsection{Materials}

Methanol (DMF, 99.9\%), deionized water, 4,4'-Azobis(4-cyanovaleric acid) (ACVA, \%75), 2dodecylsulfanylthiocarbonylsulfanyl-2-methyl propionic acid (DDMAT, \%98), and 2-hydroxyethy methacrylate (HEMA, 97\%) were purchased from Sigma Aldrich and used as received.

\subsection{Synthesis of PHEMA by RAFT polymerization}

The polymer solution was placed in the schlenk tube to polymerize the HEMA with the RAFT technique at room temperature. Nitrogen gas was passed through this solution before the initiator was added from the polymer solution. Water-methanol $(50 \%-50 \%)$ mixture was used as polymer solvent. In this study, DDMAT was chosen as a chain transfer agent. ACVA was used as initiator and polymerization was carried out at room temperature. The $[\mathrm{HEMA}]_{0} /[\mathrm{DDMAT}]_{0} /[\mathrm{ACVA}]_{0}$ ratios were varied between 100:1:0.5.

\subsection{Kinetic Studies}

PHEMA synthesis was kept at room temperature and the polymer solution in a magnetic stirrer. In order to perform kinetic studies in the polymerization of HEMA at room temperature, samples were taken by opening the solution in the polymer solution by contacting with the air at different time intervals. The ${ }^{1} \mathrm{H}-\mathrm{NMR}$ spectrum of each sample was used to determine the monomer conversion. ${ }^{1} \mathrm{H}-\mathrm{NMR}$ was calculated for the molecular weights for PHEMA.

\subsection{Measurements}

Bruker Ultra shield $300 \mathrm{MHz}$ Nuclear Magnetic Resonance (NMR) device was used as NMR system to determine monomer conversion and molecular weight in polymer samples taken at different times. The MestRenova version 6.0.2-5475 software was used to identify peak regions and peak areas of polymer samples. The polymerization solvent was dissolved in DMSO- $\mathrm{d}_{6}$ solvent and NMR spectra were taken. Fourier-transform infrared spectroscopy (ATR-FTIR) was used for each polymerization time. ATR-FTIR spectra of polymer solutions were obtained in 128 scans. 


\section{RESULTS and DISCUSSION}

\subsection{Synthesis of the PHEMA by RAFT Polymerization}

The RAFT polymerization of HEMA was carried out in the presence of the initiator (ACVA) and RAFT agent (DDMAT), in methanol/water mixture at ambient temperature for different time intervals

(Figure $1)$.

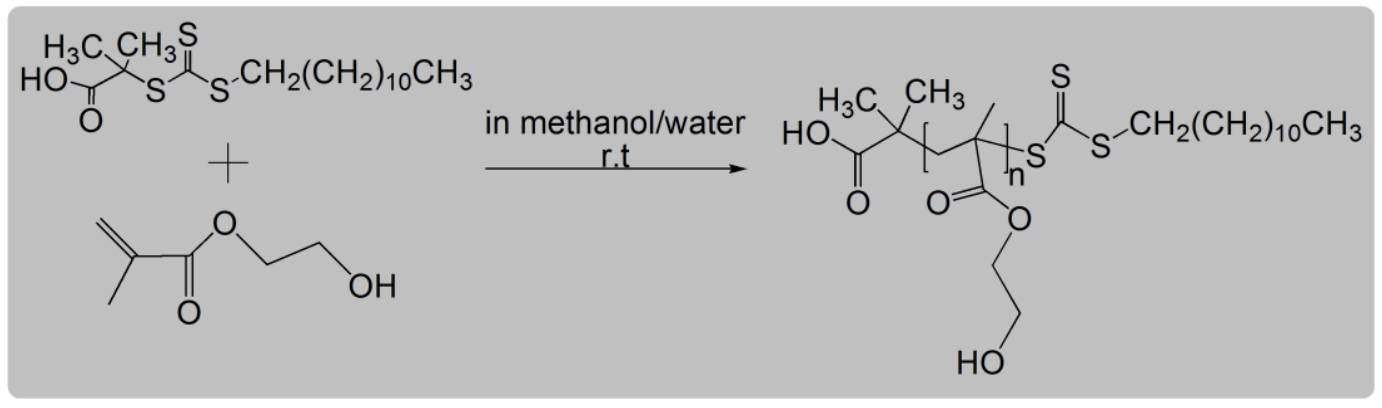

Figure 1. Preparation of PHEMA via RAFT polymerization

For the NMR technique, the polymer solution formed after 30 minutes was used as a model (Figure 2). The peaks of this polymer solution are shown as follows. The presence of all peaks of PHEMA according to the obtained spectrum may indicate that RAFT polymerization has been performed successfully.

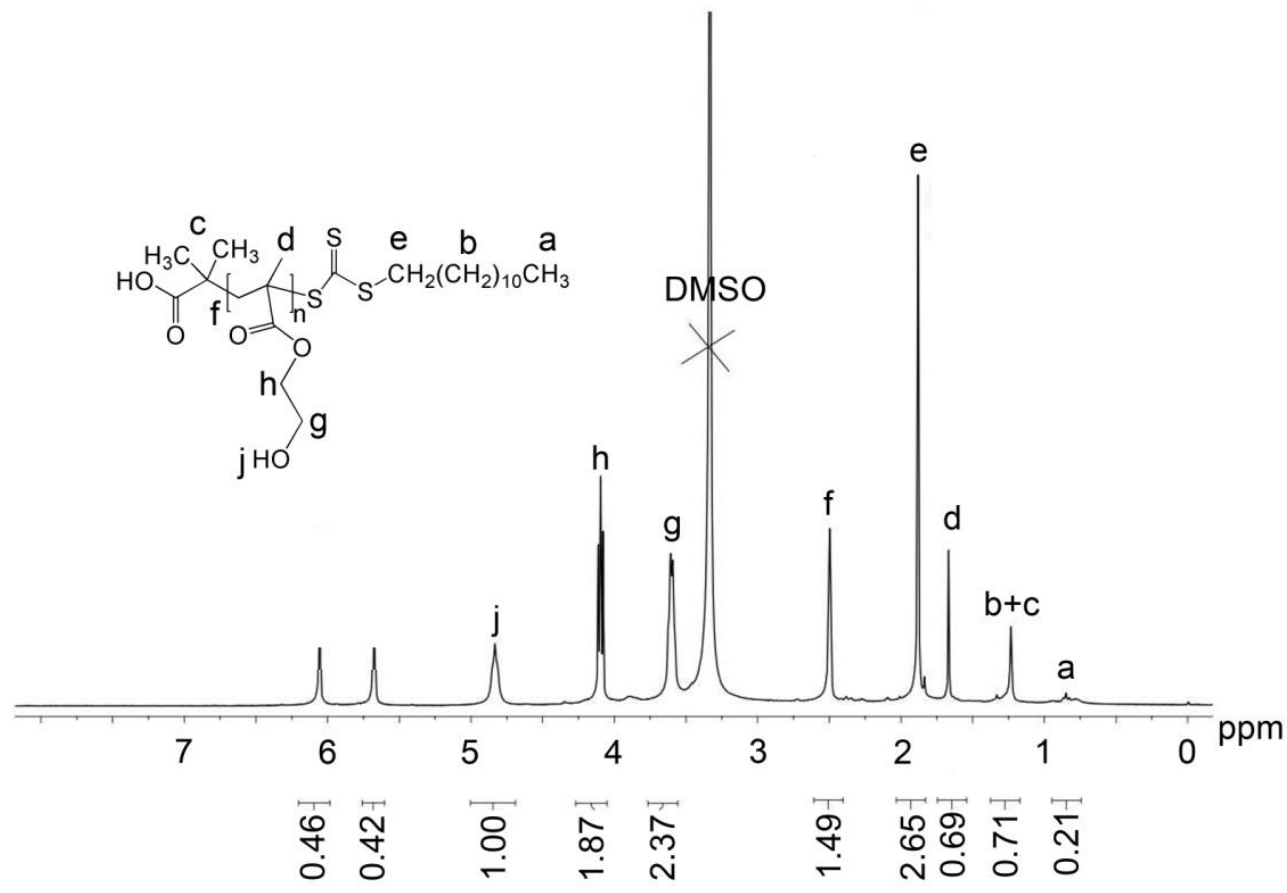

Figure 2. ${ }^{1} \mathrm{H}-\mathrm{NMR}$ spectrum of PHEMA at $30 \mathrm{~min}$ (model spectrum)

The conversion of monomers into polymer chains by time was determined by the ${ }^{1} \mathrm{H}-\mathrm{NMR}$ technique (Figure 3$)$. The conversion was calculated using the signals from the vinyl ( $\delta 5.75$ and $6.05 \mathrm{ppm}$ ) hydrogens of the unreacted HEMA, and the aliphatic hydrogen's ( $\delta 3.65 \mathrm{ppm}, \delta 4,15 \mathrm{ppm}$, and $\delta 0.98 \mathrm{ppm})$ of the PHEMA. 


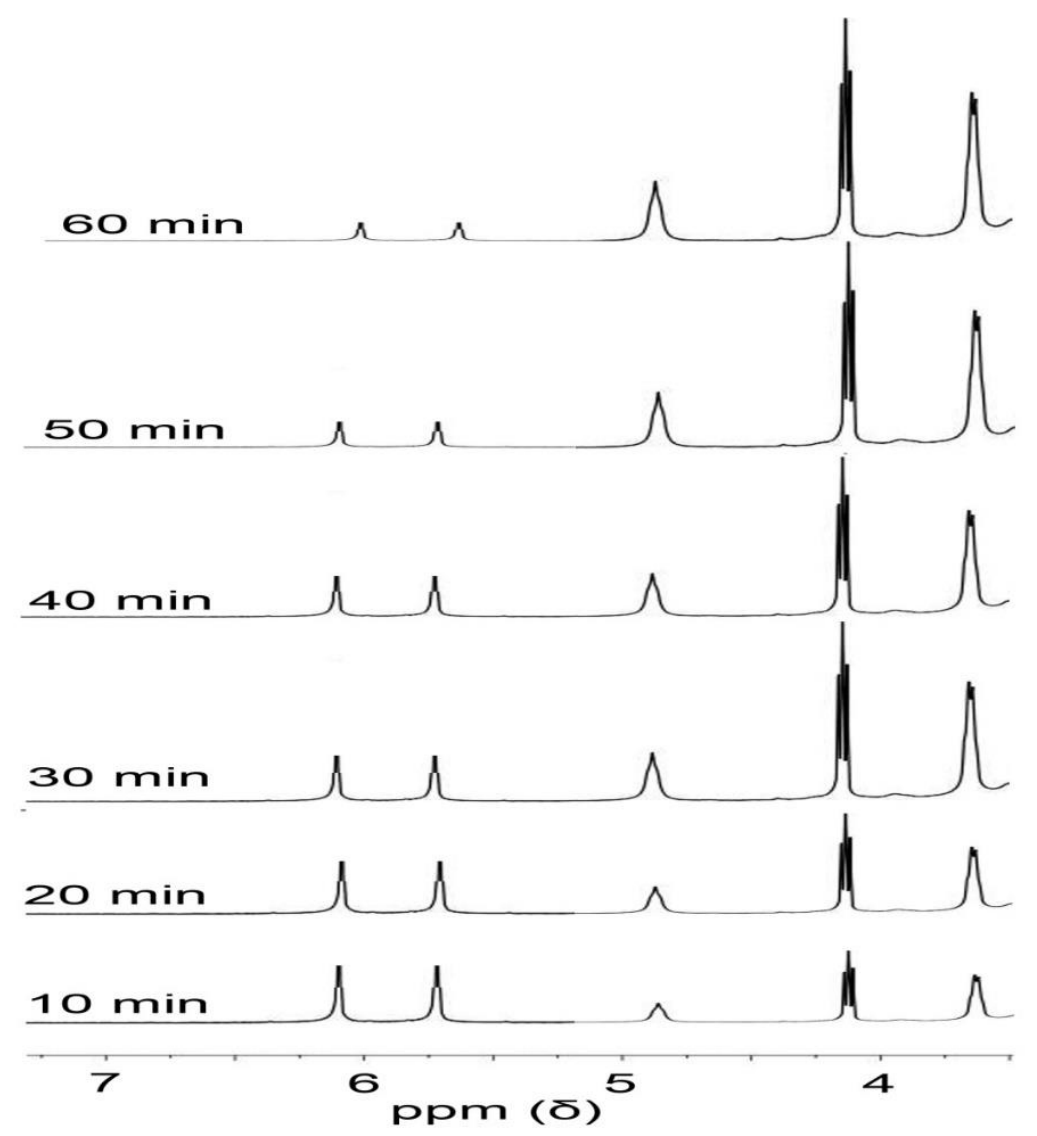

Figure 3. ${ }^{l} H-N M R$ spectra of samples taken from the polymerization solution at different polymerization times

The evidence that PHEMA is synthesized in a controlled manner can be understood by examining changes in monomer conversion over time. Monomer conversions calculated at different time intervals increased linearly with time. This supports the linear change of monomer conversion with time, which is an important feature of controlled / living polymerization techniques. In addition, monomer conversion was calculated as $92 \%$ after 1 hour in this study (Figure 4 ).

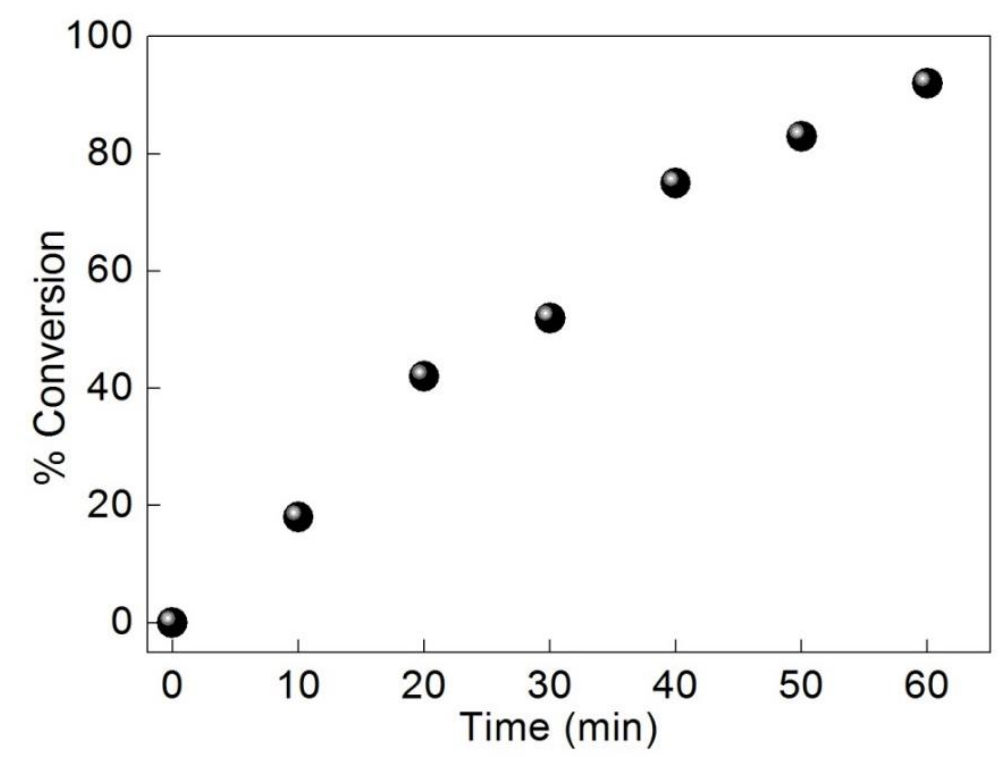

Figure 4. Time dependence change of monomer conversion for PHEMA 
A number of studies have been conducted to demonstrate that the polymer chains of PHEMA grow in a controlled manner. The molecular weights of PHEMA synthesized in these studies at specific time intervals were determined by $\mathrm{H}^{1}$ - NMR technique (Figure 5). The molecular weights were determined by the ratio of the peaks belonging to hydrogen atoms in the methyl groups in the raft agent of the peak intensities of the hydrogen atoms in the aliphatic groups in the HEMA monomer. In summary, this situation can be shown with the following equation:

$\overline{\mathrm{M}}, \mathrm{NMR}=\left[\left(I_{3.65+4.15} / 4\right] /\left(I_{0.98} / 3\right) \times \mathrm{M}_{\mathrm{M}}+\mathrm{M}_{\text {DDMAT }}\right.$

where the equation $1 ; I_{3.65}, I_{4.15}, I_{0.98}, \mathrm{M}_{\mathrm{M}}$ and $\mathrm{M}_{\text {DDMAT }}$ correspond to integrals of peak signals at $\delta 3.65$ ppm, $\delta 4,15 \mathrm{ppm}$ and $\delta 0.98 \mathrm{ppm}$ attributed to the $\mathrm{CH}_{2}$ groups of PHEMA, the methyl group of DDMAT, molecular weight of HEMA and molecular weight of DDMAT, respectively [21]. The theoretical molecular weights of PHEMA were also calculated by the following equation to compare the molecular weights obtained by the NMR technique with the molecular weight to be calculated theoretically:

$\overline{\mathrm{M}} \mathrm{n}, \mathrm{th}=[\mathrm{M}] \mathrm{o} /([\mathrm{DDMAT}] \mathrm{o}+[\mathrm{ACVA}] \mathrm{o}) \times \mathrm{M}_{\mathrm{M}} \times$ Conversion $+\mathrm{M}_{\mathrm{DDMAT}}$

Equation (2); [M]o, [DDMAT]o, [ACVA]o, $\mathrm{M}_{\mathrm{M}}$ are the initial concentration of HEMA, DDMAT, $\mathrm{Na}_{2} \mathrm{~S}_{2} \mathrm{O}_{4}$ ,the molecular weight of HEMA and molecular weight of DDMAT, respectively. The molecular weights calculated both by NMR technique and theoretically calculated show a linear increase with time. At the end of one hour, the molecular weight calculated from NMR was calculated as $8600 \mathrm{~g} / \mathrm{mol}$ and the theoretical weight calculated as $8300 \mathrm{~g} / \mathrm{mol}$. The linear increase in the molecular weights of the polymer solutions taken at different time intervals also confirms that the polymerization takes place in a controlled manner.

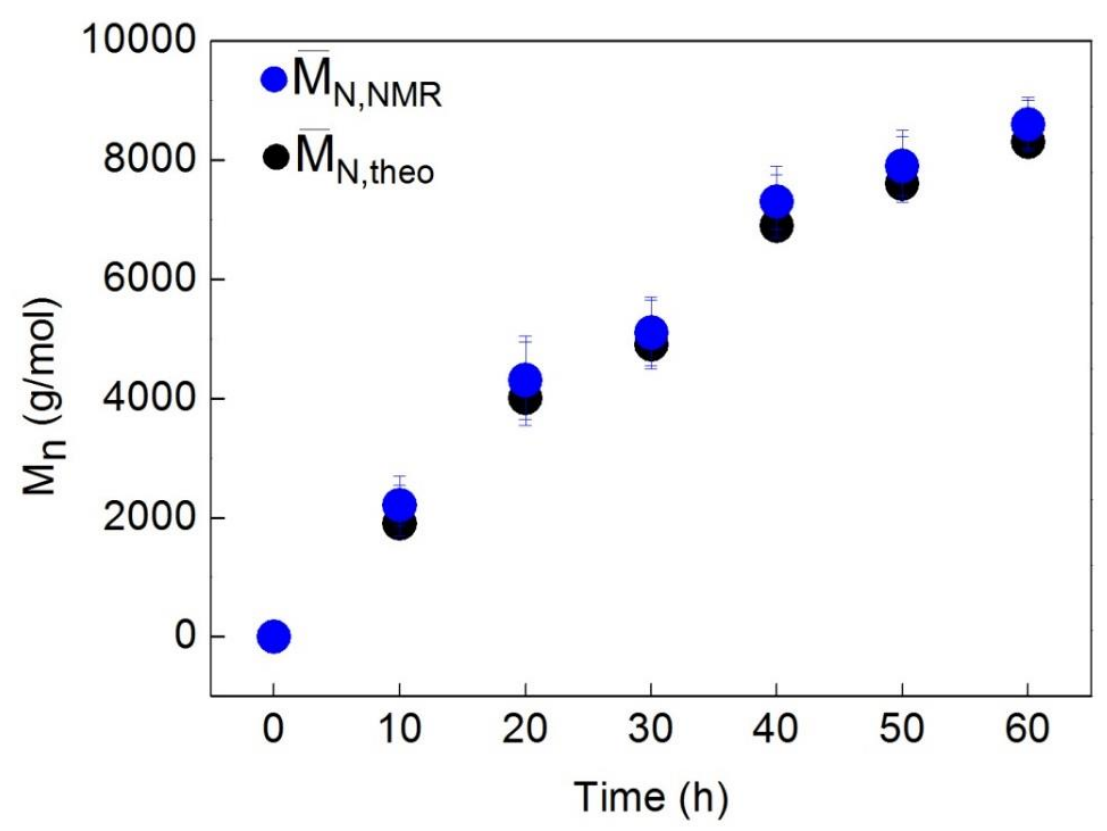

Figure 5. Time dependence of NMR and theoretical molecular weight of PHEMA

An important feature of controlled / living polymerization techniques is that they comply with first-order speed kinetics. The kinetic character of the polymerization can be determined from the monomer conversions calculated using the NMR spectra. For this purpose, a semi-logarithmic kinetic curve was drawn to show that PHEMA synthesized by RAFT polymerization was compatible with first order speed kinetics (Figure 6). The velocity constant of the slope of the semi-logarithmic kinetic curve was 0.04 and the correlation coefficient was 0.96 . The fact that the calculated correlation coefficient is close to 1 proves that the kinetics of polymerization is of first order. 


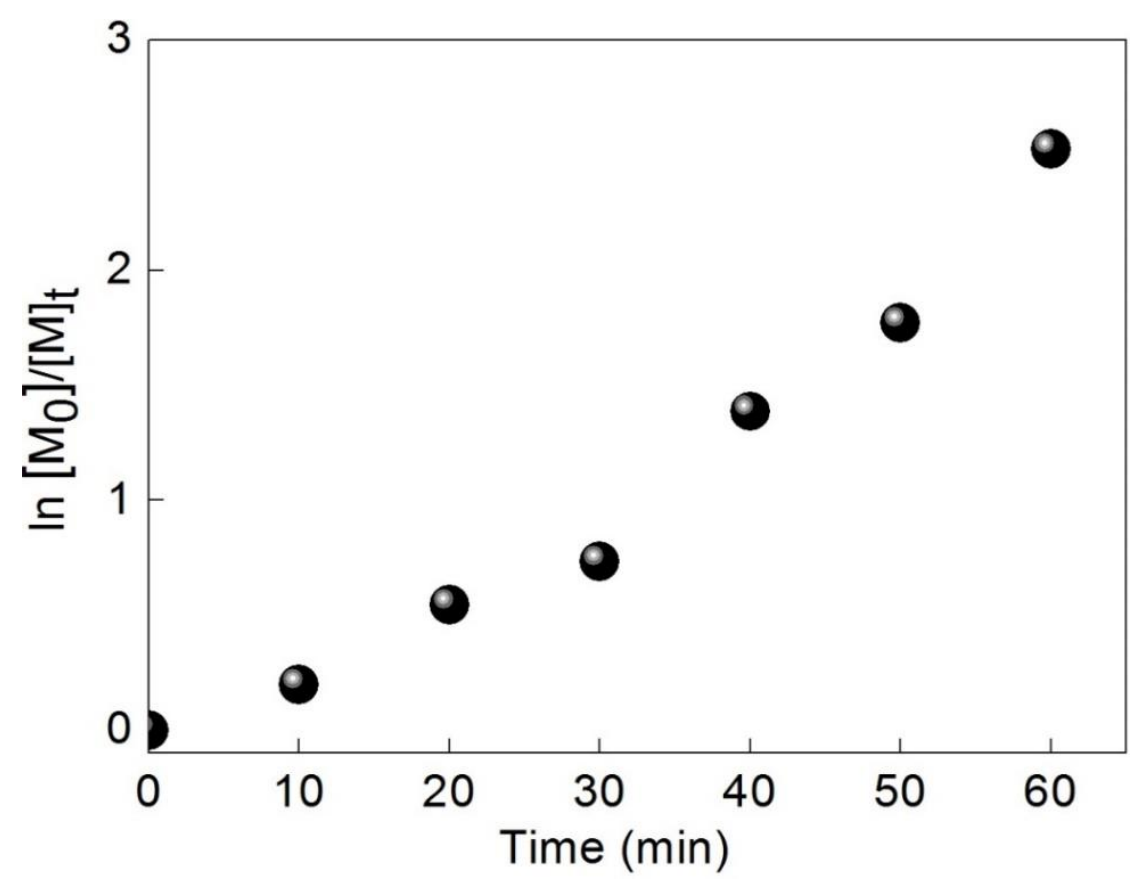

Figure 6. Semi logarithmic kinetic plots of $\ln [M]_{d} /[M]_{t}$ and time for PHEMA

Figure 7 shows the ATR-FTIR spectra of the samples taken from the solution at different polymerization times. The bands at $1636 \mathrm{~cm}^{-1}$ assigned to the $\mathrm{C}=\mathrm{C}$ bond stretching vibrations, $1700 \mathrm{~cm}^{-1}$ to $\mathrm{C}=\mathrm{O}$ bond stretch of the ester group, $3000-2850 \mathrm{~cm}^{-1}$ to the $\mathrm{C}-\mathrm{H}$ bond stretching, and $3300-3500 \mathrm{~cm}^{-1}$ to $-\mathrm{OH}$ bond the hydroxyl band. As the polymerization time increases, the band strengths of newly formed $\mathrm{CH}_{2}$ groups increase while band strengths of $\mathrm{C}=\mathrm{C}$ groups decrease in ATR-FTIR spectrum. This change in band intensities with polymerization time proves that the polymerization takes place in a controlled manner.

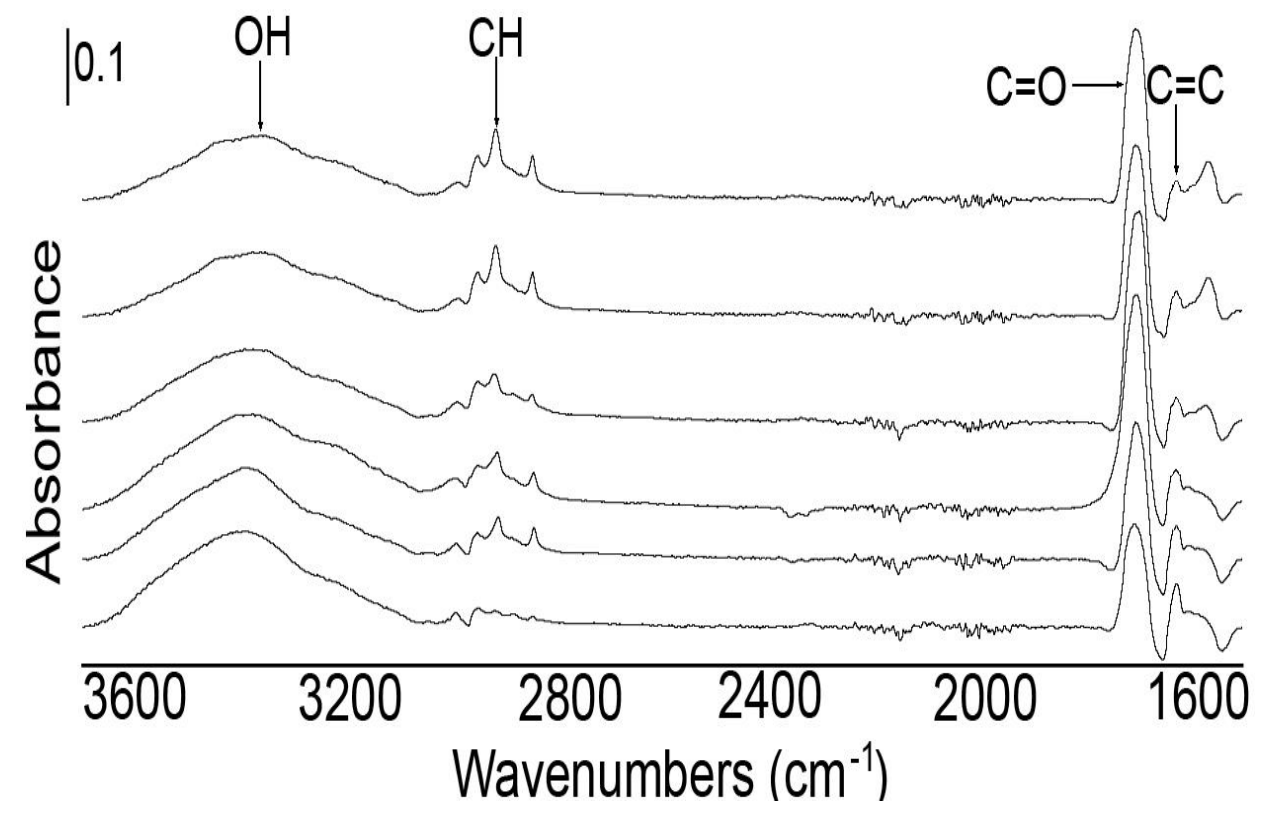

Figure 7. ATR-FTIR spectrum of PHEMA at different polymerization time 


\section{CONCLUSION}

In summary, in this study, PHEMA was synthesized at room temperature by RAFT technique. Detailed characterization of PHEMA by ATR-FTIR and NMR was performed. According to the data obtained, the HEMA monomer met the first-order speed kinetics with high conversion and the molecular weight increased linearly with time. This report has important advantages (room temperature, metal-free and high conversion) for the synthesis and characterization of HEMA-based materials. The fact that PHEMA polymers synthesized by RAFT technique at room temperature contain carboxylic acid functional end group shows that this polymer can be used in peptide, protein and bio applications easily in future studies. In addition, this polymer has the potential to be immobilized on graphene and silicon disc surfaces and used to investigate changes in surface chemistry.

\section{CONFLICTS OF INTEREST}

No conflict of interest was declared by the author.

\section{REFERENCES}

[1] Georges, M. K., Veregin, R. P. N, Kazmaier, P. M., Georges, H., "Narrow molecular weight resins by a free-radical polymerization process", Macromolecules, 26(11): 2987-2988, (1993).

[2] Hawker, C. J., Bosman, A., W, Harth, E., "New Polymer Synthesis by Nitroxide Mediated Living Radical Polymerizations", Chem. Rev., 101(12): 3661-3688, (2001).

[3] Kato, M., Kamigaito, M., Sawamoto, M., Higashimura. T., "Polymerization of Methyl Methacrylate with the Carbon Tetrachloride/Dichlorotris (triphenylphosphine) ruthenium(II) /Methylaluminum Bis(2,6-di-tert-butylphenoxide) Initiating System: Possibility of Living Radical Polymerization”, Macromolecules, 28(5): 1721-1723, (1995) .

[4] Wang, J. S., Matyjaszewski, K., "Controlled/"living" radical polymerization. atom transfer radical polymerization in the presence of transition-metal complexes", J. Am. Chem. Soc., 117(20): 5614$5615,(1995)$.

[5] Chiefari. J., Chong, Y. K., Ercole, F., Krstina, J., Jeffery, J., Le, T. P. T., Mayadunne, R. T. A., Meijs, F. G., Moad, C. L., Moad, G., Rizzardo, E., Thang, H.S., "Living Free-Radical Polymerization by Reversible Addition-Fragmentation Chain Transfer: The RAFT Process", Macromolecules, 31(16): 5559-5562, (1998).

[6] Bütün, V., Bennett, C. E., Vamvakaki, M., Lowe, A. B., Billingham, N. C., Armes, S. P., "Selective betainisation of tertiary amine methacrylate block copolymers", J. Mater. Chem., 7(9):1693-1965, (1997).

[7] Yildirim, E., Turan, E., Caykara, T., "Construction of myoglobin imprinted polymer films by grafting from silicon surface”, J. Mater. Chem., 22:636-642, (2012).

[8] Cimen, D., Caykara, T., "Biofunctional oligoN-isopropylacrylamide brushes on silicon wafer surface", J. Mater. Chem., 22:13231-13238, (2012).

[9] Boyer, C., Bulmus, V., Davis, T.P., Ladmiral, V., Liu, J., Perrier, S., "Bioapplications of RAFT Polymerization", Chem. Rev., 109(11): 5402-5436, (2009).

[10] Jennings, J., He, G., Howdle, S. M., Zetterlund, P. B., "Block copolymer synthesis by controlled/living radical polymerisation in heterogeneous systems", Chem. Soc. Rev., 45: 50555084, (2016). 
[11] Hill, M. G., Carmean, R. N., Sumerlin, B. S., "Expanding the Scope of RAFT Polymerization: Recent Advances and New Horizons", Macromolecules, 48(16): 5459-5469, (2015).

[12] Moad, G., "RAFT polymerization to form stimuli-responsive polymers", Polym. Chem., 8:177-219, (2017).

[13] Cobo, I., Li, M., Sumerlin, B. S., Perrier, S., "Smart hybrid materials by conjugation of responsive polymers to Biomacromolecules", Nat. Mater., 14:143-159, (2015).

[14] Flynn, L., Dalton, P. D., Shoichet, M. S., "Fiber templating of poly(2-hydroxyethyl methacrylate) for neural tissue engineering", Biomaterials, 24(23): 4265-72, (2003).

[15] Robinson, K. L., Khan, M. A., Banez, M. V. P., Wang, X. S., Armes, S. P. , "Controlled Polymerization of 2-Hydroxyethyl Methacrylate by ATRP at Ambient Temperature", Macromolecules, 34:3155-3158, (2001).

[16] Peng, Q., M. Y. Lai, D.M.Y, E. T. Kang, E.T., Neoh K.G., "Preparation of Polymer-Silicon(100) Hybrids viaInterface-Initiated Reversible Addition-Fragmentation Chain-Transfer (RAFT) Polymerization", Macromolecules, 39: 5577-5582, (2006).

[17] Xinming, L., Yingde, C., Lloyd, A. W., Mikhalovsky, S. V., Sandeman, S. R., Howel, C.A., Liewen, L., "Polymeric hydrogels for novel contact lens-based ophthalmic drug delivery systems: A review", Cont. Lens Anterior Eye., 31(2): 57-64, (2008).

[18] Das, D., Pal, S., "Dextrin/poly (HEMA): $\mathrm{pH}$ responsive porous hydrogel for controlled release of ciprofloxacin”, Int. J. Biol. Macromol., 72:171-178, (2015).

[19] Gómez, M. L., Gallastegui, A., Spesia, M.B., Montejano, A. H., Williams, R. J., Previtali, C. M., "Synthesis of poly (HEMA-co-AAm) hydrogels by visible-light photopolymerization of aqueous solutions containing aspirin or ibuprofen: analysis of the initiation mechanism and the drug release" , Polym. Adv. Technol., 28(4):435-442, (2017).

[20] Cadotte, A. J., DeMarse, T. B., "Poly-HEMA as a drug delivery device for in vitro neural networks on micro-electrode arrays", J. Neural Eng., 2(4):114-122, (2005).

[21] Shanmugam, X. S., Duonga, H., Boyer C. T, "Organo-photocatalysts for photoinduced electron transfer-reversible addition-fragmentation chain transfer (PET-RAFT) polymerization”, Polym. Chem., 6:5615-5624, (2015). 